\title{
Incompletely and completely healed duodenal ulcers' outcome in maintenance treatment: a double blind controlled study
}

\author{
P PAOLUZI, G RICOTTA, F RIPOLI, F PROIETTI, E ZACCARDELLI, \\ R CARRATU, AND A TORSOLI
}

From the Cattedra di Gastroenterologia I, Università La Sapienza, Rome, Italy

SUMmaRY A six month, double blind, controlled study was performed in 107 asymptomatic duodenal ulcer patients who, after short term cimetidine treatment, showed complete or incomplete endoscopic healing. Patients were stratified according to the type of healing and randomly allocated to cimetidine (200 mg at lunch, $400 \mathrm{mg}$ at bedtime) or placebo. Endoscopic examinations were carried out after six months or when symptoms recurred. Eighty seven patients completed the maintenance trial. Of the 56 patients admitted to the study with complete healing, 30 were placed on cimetidine and 26 on placebo. Of the 31 patients admitted with incomplete healing, 15 were placed on cimetidine, and 16 on placebo. Results showed that, regardless of maintenance treatment, patients with incompletely healed ulcers had a higher ulcer crater recurrence rate, than patients with complete healing $(71 \%$ vs $34 \% ; \mathrm{p}<0.005)$. A significantly higher ulcer crater recurrence was observed in incompletely healed ulcer patients, even when cimetidine or placebo treatment groups were considered separately. Irrespective of the type of healing, ulcer crater recurrence was more frequent in placebo treated patients than in those treated with cimetidine $(67 \%$ vs $29 \%$; $<<0.001)$. We conclude that, in order to prevent a high ulcer recurrence rate, maintenance treatment should start only after the assessment of a complete endoscopic healing of duodenal ulcers.

The endoscopic definition of the healing of peptic ulcers lacks uniformity and this lack of universally accepted criteria could affect the scientific and clinical results of ulcer treatment.

Ippoliti et al $^{1}$ found that, when ulcer healing was considered as disappearance of the ulcer crater, the ulcer healing rate, after four weeks' antacid treatment, was $86 \%$. When on the other hand ulcer healing was considered as absence of both ulcer and erosions - that is, breaks in the mucosa without a fibrous base, the rate decreased to $52 \%$

Miyake $e t a l^{2}$ described different stages of gastric ulcer healing. The third and fourth stages were called the palisade scar stage and the cobblestone stage, respectively. These are similar to the red and white scar stages described by Sakita. ${ }^{3}$

In previous studies ${ }^{4-7}$ on the effects of various

Address for correspondence: Professor Paolo Paoluzi. Cattedra di Gastroenterologia. II Clinica Medica. Università di Roma. Viale Policlinico.00185 Roma, Italy.

Received for publication 21 September 1984 drugs in duodenal ulcer treatment, we also described two different stages of ulcer healing, incomplete and complete healing. Incomplete healing was defined as incomplete epithelial replacement or a congested, hyperaemic and fragile scarring area. Complete healing was defined as normal mucosa or a scarring area with pale or whitish-looking mucosa, but with a normal restored epithelium. These two stages of ulcer healing correspond, in fact, to the red and white scar stages of Sakita ${ }^{3}$ and to the palisade and cobblestone stages of Miyake et al. ${ }^{2}$

The aim of the present study was to establish the subsequent clinical and anatomical outcome of completely versus incompletely healed duodenal ulcers in a controlled maintenance trial.

\section{Patients}

\section{METHODS}

One hundred and seven consecutive, symptom free, duodenal ulcer patients ( 81 men, 26 women, age 
range $18-70$ years) were admitted to this maintenance trial. The patients had previously undergone an eight week full dosage treatment with cimetidine and, at endoscopic control, showed either incomplete or complete healing. The ascertainment of ulcer healing was independently assessed by two members of the endoscopic team (PP and FR). Interobserver variation did not exceed $5 \%$ of the cases. Only patients to whom both observers had given the same definition of healing were included in the study.

Patients with other gastrointestinal diseases or with renal, hepatic or cardiorespiratory malfunctions were not included in the study. Patients taking analgesics or antiphlogistic drugs and pregnant or nursing women were also excluded.

The maintenance study was double blind, randomised for treatment (cimetidine or placebo) and stratified according to healing type (complete or incomplete). The patients were allocated to either cimetidine $600 \mathrm{mg} /$ day (200 mg tablets; one at lunch, two at bedtime) or placebo tablets, identical in number and appearance, for a period of six months. No other treatment was allowed, with the exception of antacids, when necessary.

Every month patients returned to report on symptoms, the number of antacids used, the emergence of possible untoward effects and to control the number of unused tablets. Blood samples were also collected in order to determine the concentrations of serum alkaline phosphatase, transaminases, bilirubin, and serum creatinine.

Endoscopic controls were carried out at the end of the period or earlier, in the case of clinical relapse. Relapse was defined as recurrence of epigastric pain which was not relieved after at least three days of antacid treatment.

Endoscopic findings were defined as improved, when incomplete healing progressed to complete healing, unchanged, when the appearance was immodified, with regard to the endoscopy done at the end of pretrial treatment, and as ulcer recurrence, when a definite ulcer crater was visible. Final judgment was reached on the basis of photographic records by one of us (PP), who was unaware of the patient's name and clinical course.

Olympus fibrescopes, model GIF- $\mathrm{D}_{3}$, were used. This model allows a close, and therefore magnified vision, of minimal mucosal lesions, because of the presence of focus adjustment.

Informed consent was obtained by all patients. The study was carried out according to the principles of the Helsinki Declaration.

Statistical analysis of the results was calculated using the $\chi^{2}$ method, Fisher's exact test, Wilcoxon's rank test and Student's $t$ test for unpaired data. Results were considered statistically significant when $p$ values were less than $0 \cdot 05$.

\section{Results}

A few patients reported mild side effects, but this was not significantly higher in either group. Only one patient in the placebo group stopped treatment because of dizziness. A slight transient increase in serum creatinine values was observed in five patients on cimetidine and in two patients receiving placebo but these biochemical changes did not cause patient withdrawal from the study.

Of the 107 patients admitted to the study, 20 dropped out; one because of dizziness and one because of myocardial ischaemia, both patients were on placebo, and the others for non-medical reasons, as shown in Table 1.

Table 1 Causes of drop-outs in the four groups of patients

\begin{tabular}{|c|c|c|c|c|}
\hline & \multicolumn{2}{|c|}{ Complete healing } & \multicolumn{2}{|c|}{ Incomplete healing } \\
\hline & Cimetidine & Placebo & Cimetidine & Placebo \\
\hline Myocardial ischaemia & - & 1 & - & - \\
\hline $\begin{array}{l}\text { Discontinuation of } \\
\text { treatment }\end{array}$ & 1 & 4 & 2 & 1 \\
\hline $\begin{array}{l}\text { Refusal of endoscopic } \\
\text { control }\end{array}$ & 2 & 2 & 4 & 2 \\
\hline Untoward effects & - & 1 & - & - \\
\hline Total & 3 & 8 & 6 & 3 \\
\hline
\end{tabular}

Table 2 Distribution and clinical data of patients

\begin{tabular}{|c|c|c|c|c|}
\hline & \multicolumn{2}{|l|}{ Complete healing } & \multicolumn{2}{|l|}{ Incomplete healing } \\
\hline & Cimetidine & Placebo & Cimetidine & Placebo \\
\hline Patients (no) & 30 & 26 & 15 & 16 \\
\hline Male/Female & $24 / 6$ & $19 / 7$ & $11 / 4$ & $11 / 5$ \\
\hline Age $(y r$, mean $\pm S D)$ & $41 \cdot 8 \pm 14 \cdot 7$ & $46 \pm 15 \cdot 7$ & $42 \cdot 3 \pm 11 \cdot 1$ & $44 \cdot 7 \pm 12 \cdot 3$ \\
\hline \multirow{2}{*}{$\begin{array}{c}\text { Disease duration (yr) median: } \\
\text { range: }\end{array}$} & $9 \cdot 5$ & $6 \cdot 5$ & 9 & $8 \cdot 5$ \\
\hline & $1-21$ & $1-19$ & $1-31$ & $1-32$ \\
\hline Smokers $(\%)$ & $15(50)$ & $13(50)$ & $7(46 \cdot 6)$ & $10(62 \cdot 5)$ \\
\hline
\end{tabular}


Table 3 Clinical and endoscopic outcome in the four groups of patients following long term treatment

\begin{tabular}{|c|c|c|c|c|c|c|c|c|c|c|c|c|c|c|}
\hline \multirow[b]{3}{*}{ Healing } & \multirow[b]{3}{*}{ Treatment } & \multicolumn{4}{|c|}{ Symptomatic patients } & \multicolumn{4}{|c|}{ Asymptomatic patients } & \multicolumn{5}{|c|}{ Cumulative results } \\
\hline & & \multicolumn{4}{|c|}{ Endoscopic findings } & \multicolumn{4}{|c|}{ Endoscopic findings } & \multicolumn{5}{|c|}{ Endoscopic findings } \\
\hline & & (no) & 1 & $U$ & $U R$ & (no) & $I$ & $U$ & $U R$ & (no) & $l$ & $U$ & $U R$ & $U R \%$ \\
\hline \multirow[t]{3}{*}{ Complete } & CMT & 2 & - & 0 & 2 & 28 & - & 25 & 3 & 30 & - & 25 & 5 & 17 \\
\hline & PL & 9 & - & 0 & 9 & 17 & - & 12 & 5 & 26 & - & 12 & 14 & 54 \\
\hline & Total & 11 & - & 0 & 11 & 45 & - & 37 & 8 & 56 & - & 37 & 19 & 34 \\
\hline \multirow[t]{3}{*}{ Incomplete } & CMT & 5 & 1 & 0 & 4 & 10 & 5 & 1 & 4 & 15 & 6 & 1 & 8 & 53 \\
\hline & PL & 8 & 0 & 0 & 8 & 8 & 0 & 2 & 6 & 16 & () & 2 & 14 & 88 \\
\hline & Total & 13 & 1 & 0 & 12 & 18 & 5 & 3 & 10 & 31 & 6 & 3 & 22 & 71 \\
\hline
\end{tabular}

$\mathrm{CMT}=$ cimetidine $\mathrm{PL}=$ placebo $\mathrm{I}=$ improved $\mathrm{U}=$ unchanged: $\mathrm{UR}=$ ulcer recurrence

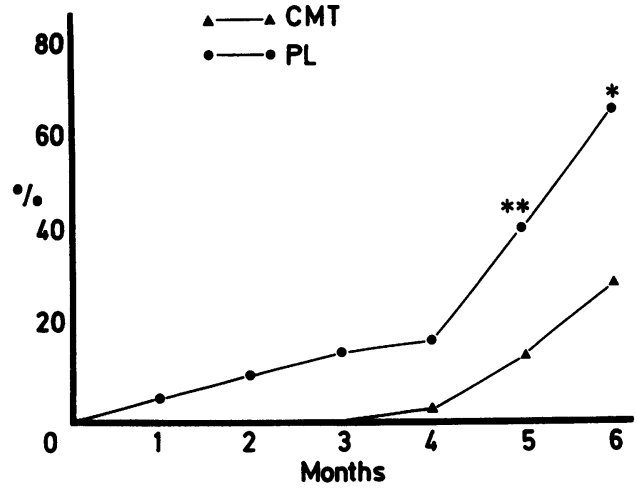

Fig. 1 Percentage cumulative ulcer recurrence in patients treated with cimetidine (CMT) or placebo $(P L)$, regardless of healing type. ${ }^{*}$ overall recurrences (symptomatic + asymptomatic) $(p<0.001)$. ** symptomatic recurrences (up to five months) $(p<0.01)$.

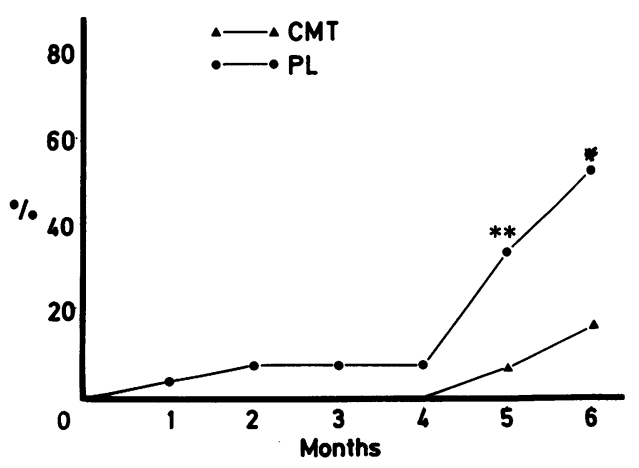

Fig. 2 Percentage cumulative ulcer recurrence in patients with complete healing, treated with cimetidine $(C M T)$ or placebo $(P L)$. * overall recurrences (symptomatic + asymptomatic) $(p<0 \cdot 005)$. ${ }^{* *}$ symptomatic recurrences (up to five months) $(p<0.005)$.
The distribution and characteristics of the 87 patients completing the study are shown in Table 2. Of the 56 patients admitted to the trial with complete duodenal ulcer healing, 30 were allocated to cimetidine and 26 to placebo. Of the 31 patients with incompletely healed duodenal ulcers, 15 were allocated to cimetidine and 16 to placebo.

No significant differences were observed between the four groups as far as age, sex, duration of the disease and smoking habits were concerned. The clinical and endoscopic outcome of the four groups of patients, following long term treatment, are reported in Table 3.

Regardless of the healing type, a significantly lower cumulative ulcer recurrence rate was observed in cimetidine treated patients $(13$ out of $45 ; 29 \%)$ than in those on placebo ( 28 out of $42 ; 67 \%$; $\mathrm{p}<0.001)$. Moreover, in patients on cimetidine, symptomatic ulcer recurrences were fewer (six out

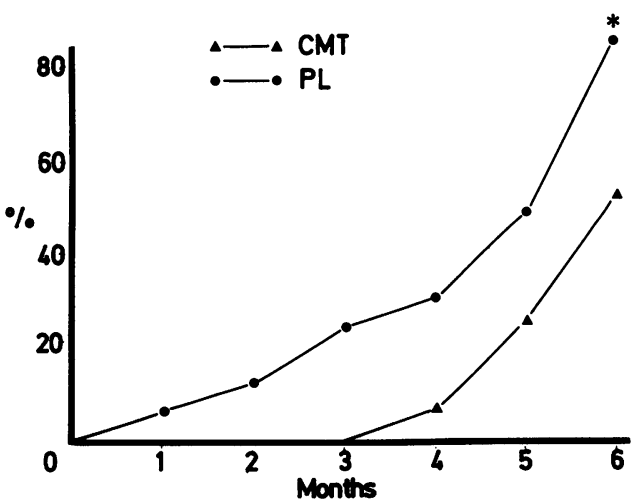

Fig. 3 Percentage cumulative ulcer recurrence in patients with incomplete healing, treated with cimetidine $(C M T)$ or placebo $(P L) .{ }^{*}$ overall recurrences (symptomatic + asymptomatic) $(p<0.05)$. 
of $45 ; 13 \%)$ when compared with patients on placebo (17 out of $42 ; 40 \% ; \mathrm{p}<0.01)$ and also developed later (Fig. 1).

Cimetidine still proved more effective than placebo, in the two subgroups of completely $(17 \%$ vs $54 \%$, respectively) and incompletely (53\% vs $88 \%$, respectively) healed ulcer patients (Figs. 2, 3).

Regardless of the type of treatment (Fig. 4), patients with incompletely healed ulcers showed a higher cumulative ulcer recurrence rate than patients with completely healed ulcers $(71 \%$ vs $34 \%$, respectively; $\mathrm{p}<0.005$ ).

Considering the healing type in relation to the type of treatment, incompletely healed ulcer patients still showed a higher ulcer recurrence rate than completely healed ulcer patients in the two

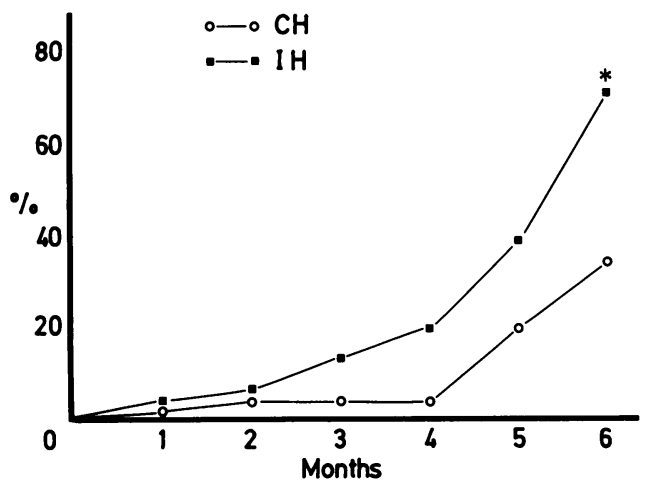

Fig. 4 Percentage cumulative ulcer recurrence in patients with complete $(\mathrm{CH})$ or incomplete $(\mathrm{IH})$, regardless of treatment. * cumulative recurrences (symptomatic + asymptomatic) $(p<0 \cdot 005)$.

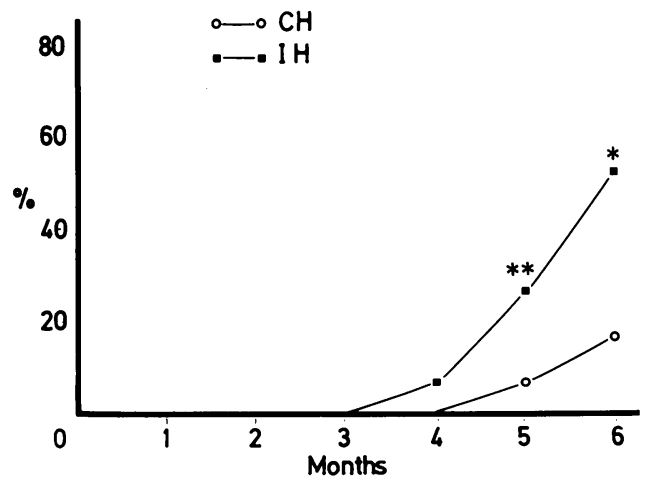

Fig. 5 Percentage cumulative ulcer recurrence in patients with complete $(\mathrm{CH})$ or incomplete healing $(\mathrm{IH})$, after treatment with cimetidine. ${ }^{*}$ overall recurrences (symptomatic + asymptomatic $)(p<0 \cdot 005) .{ }^{* *}$ symptomatic recurrences (up to five months) $(p<0.05)$. subgroups on cimetidine $(54 \%$ vs $17 \%$, respectively; $\mathrm{p}<0.005)$ and on placebo $(88 \%$ vs $54 \%$, respectively; $p<0.05$ ) Figs. 5,6). Moreover, in patients on cimetidine, those with incompletely healed ulcers showed a higher symptomatic ulcer recurrence rate than those with completely healed ulcers $(27 \%$ vs $7 \%$, respectively; $p<0 \cdot 05$ ) (Fig. 5), even if six out of 15 progressed to complete healing.

Sex, age, and duration of the disease did not appear to significantly influence the frequency of ulcer recurrence.

When all patients in the study were taken into consideration, it was noted that smokers showed a slightly higher, though not significant, ulcer recurrence rate than non-smokers (55\% vs $38 \%)$. Also when the cimetidine treated patients were considered, there was no significant difference between smokers and non-smokers (32\% vs $26 \%)$. In the placebo treated group, however, smokers did show a significantly higher ulcer recurrence rate $(47 \%$ vs $22 \% ; \mathrm{p}<0.05)$. This was still true in the subgroup with incomplete healing on placebo $(100 \%$ smokers vs $57 \%$ non-smokers; $\mathrm{p}<0.05$ ).

\section{Discussion}

Cimetidine doses of both $400 \mathrm{mg}$ or $800 \mathrm{mg} /$ day were shown to be equally effective in previous trials on maintenance treatment of duodenal ulcer. ${ }^{8}$ In this study, we used an intermediary daily dosage of 600 $\mathrm{mg}$, corresponding to half the dosage $(1 \cdot 2 \mathrm{~g} /$ day $)$ administered in the short term pretrial treatment.

Results from the present study confirm that, as reported in similar studies, ${ }^{9-14}$ cimetidine is effective in the prevention of ulcer recurrence. Both symp-

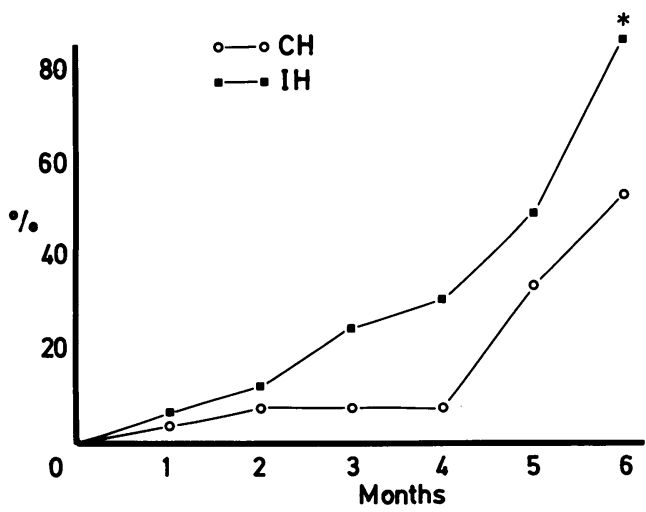

Fig. 6 Percentage cumulative ulcer recurrence in patients with complete $(\mathrm{CH})$ or incomplete healing $(\mathrm{IH})$ after treatment with placebo. ${ }^{*}$ overall recurrences (symptomatic + asymptomatic $)(p<0.05)$. 
tomatic and asymptomatic ulcer recurrences are significantly more frequent after placebo than cimetidine maintenance treatment. An additional result of our study shows that, when no effective drug is administered, smoking is a negative prognostic factor in ulcer recurrence and that cimetidine treatment, on the other hand, seems to reduce the importance of this factor.

The above mentioned results indicate that maintenance treatment can be useful in reducing ulcer recurrence.

Independent of the type of follow up treatment, however, when short term, full dosage treatment should be discontinued and how to judge this is not clearly established. The lack of standard criteria in the endoscopic assessment of ulcer healing makes the problem more complicated.

This may even lead to relevant variations in the results of studies on the efficacy of ulcer healing drugs. In a previous controlled study, ${ }^{6}$ concerning the efficacy of cimetidine in the treatment of duodenal ulcers, at a dose of $0.8 \mathrm{~g} /$ day for twomonths, healing of the ulcer crater was observed in $82 \%$ of patients treated with cimetidine and in $39 \%$ of patients receiving placebo, the difference being statistically significant $(p<0 \cdot 01)$. When only complete healing, as described in this study, was considered, however, values as low as $27 \%$ and $17 \%$, respectively, were observed and the difference was no longer statistically significant.

The definition of incomplete healing does not refer to improvement or to a marked reduction in the size of the ulcer crater, but, instead, indicates the disappearance of the crater as well as the persistence of residual, even minimal, areas of mucosa not displaying complete epithelialisation. Most of the time, these areas can only be recognised by close, and therefore magnified, endoscopic vision. Our definitions are comparable to those of Sakita $^{3}$ who, in 1972 , described the two different stages of gastric ulcer healing as red and white scars.

Incompletely healed lesions sometimes progress to complete healing but, at other times, persist for another four to eight weeks, with full dose treatment. It is, therefore, not at all clear whether incomplete healing should be considered as a normal transitional phase leading to complete healing or whether it is a chronic stage of the disease, in which the aggressive and defensive factors are balanced. If the first hypothesis was the case, there would be no reason to continue treatment at the full dose as the healing would naturally progress towards complete healing and, therefore, maintenance treatment could be started. If, however, incomplete healing refers to a slow repairing or resistant lesion, then the full dose treatment should be continued.
Results from the present study seem to support this latter hypothesis. In fact, patients with incompletely healed ulcers showed a higher ulcer recurrence rate than those with completely healed ulcers. Moreover, incomplete healing reduced the efficacy of cimetidine treatment and increased the already higher risk of ulcer recurrence in smokers treated with placebo.

Despite the different test conditions, these results seem to agree with those of Miyake et al, ${ }^{15}$ who, following the definitions of Sakita, ${ }^{3}$ observed a significantly higher recurrence rate in cases with red scar healing (incomplete healing) than in those with white scar healing (complete healing), in their study of gastric ulcer patients treated for six months with sucralfate, and endoscopically controlled at two month intervals for 18 months.

In conclusion, the data observed in our study show that incomplete healing leads to a higher duodenal ulcer recurrence rate compared with complete healing. Perhaps, therefore, short term treatment should not be discontinued until complete endoscopic healing has been ascertained, and it is suggested that a controlled trial of prolonged treatment of incompletely healed ulcers is needed versus no such prolonged treatment.

The authors wish to thank Mrs A de Rossi for valuable technical assistance. This study was presented at the Spring Meeting of the British Society of Gastroenterology, London, 1983 and published in abstract form (Gut 1983; 24: A469).

\section{References}

1 Ippoliti AF, Sturdevant RAL, Isenberg JI et al. Cimetidine versus intensive antacid therapy for duodenal ulcer. A multi-center trial. Gastroenterology 1978; 74: 393-5.

2 Miyake T, Suzaki T, Oishi M. Correlation of gastric ulcer healing features by endoscopy, stereoscopic microscopy and histology, and a reclassification of the epithelial regenerative process. Dig Dis Sci 1980; 25: 8-14.

3 Sakita T. Chronic ulcer of the stomach. In: Gastroendoscopy. Tokyo: International Medical Foundation of Japan, 1972: 49. Quoted by Miyake T, Suzaki T, Oishi M. Correlation of gastric ulcer healing features by endoscopy, stereoscopic microscopy and histology, and a reclassification of the epithelial regenerative process. Dig Dis Sci 1980; 25: 8-14.

4 Paoluzi P. Letter to the editor. Ital J Gastroenterol 1978; 10: 121.

5 Zaccardelli E, Proietti F, Ricotta G, Carratù R, Paoluzi P. Trattamento dell'ulcera duodenale con differenti dosi di cimetidina. Risultati di uno studio clinico endoscopico. Clin Terap 1980; 95: 279-87. 
6 Carratù R, Paoluzi P, Kohn A, Delle Fave G. Incomplete duodenal ulcer healing with cimetidine. Gastroenterology 1982; 82: 1029.

7 Paoluzi P, Ricotta G, Gianfrancesco G, Zaccardelli E, Ripoli F, Carratù R. Pirenzepine and cimetidine in the treatment of duodenal ulcer: results of a double blind trial. Ital J Gastroenterol 1982; 14: 225-7.

8 Burland WL, Hawkins BW, Beresford J. Cimetidine treatment for the prevention of recurrence of duodenal ulcer: an international collaborative study. Postgrad Med J 1980; 56: 173-6.

9 Gray GR, Smith IS, Mackenzie I, Gillespie G. Longterm cimetidine in the management of severe duodenal ulcer dyspepsia. Gastroenterology 1978; 74: 397-401.

10 Berstad A, Aadland E, Carslen E, Myren J, Sembl S, Kruse-Jensen A. Maintenance treatment of duodenal ulcer patients with a single bedtime dose of cimetidine. Scand J Gastroenterol 1979; 14: 827.
11 Bianchi Porro S, Petrillo M. Long-term prophylactic treatment with cimetidine in duodenal ulceration. Ital J Gastroenterol 1979; 11: 181.

12 Bardhan KD, Saul DM, Edwards JL, Smith PM, Maggie SJ, Willie JH. Double-blind comparison of cimetidine and placebo in the maintenance healing of chronic duodenal ulceration. Gut 1979; 20: 158-62.

13 Dronfield MW, Batchelor AJ, Larkworthy W, Langman MJS. Controlled trial of maintenance cimetidine treatment in healed duodenal ulcer: short and longterm effects. Gut 1979; 20: 526-30.

14 Hansky J, Korman MG. Long-term cimetidine in duodenal ulcer disease. Dig Dis Sci 1979; 24: 465-7.

15 Miyake T, Ariyoshi J, Suzaki T, Oishi M, Sakai M, Ueda S. Endoscopic evaluation of the effect of sucralfate therapy and other clinical parameters on the recurrence rate of gastric ulcer. Dig Dis Sci 1980; 25: $1-7$. 